\title{
Investigation of Furin inhibition to block SARS-CoV-2 spike protein cleavage and Structural stability via molecular docking and molecular dynamics simulations
}

\author{
Jaganathan Ramakrishnan, Archana Chinnamadhu, Kumaradhas Poomani* \\ Laboratory of Biocystallography and Computational Molecular Biology, Department of Physics, \\ University, Salem-636 011, India \\ rjaganphy@gmail.com
}

SARS-CoV-2 (Severe Acute Respiratory Syndrome-Corona Virus 2) spike protein which is the viral protein causes human cell infections by binding to host cell receptor ACE2 and initiates the membrane fusion. After the entry process the S-protein needs to be called up and activated by the furin and TMPRSS2 which are the cellular proteases, stimulates the virus entry into the human cells [1][2]. By inhibiting the furin protease leads to supress the spike protein activation in the host cell. The present study aims to understand the intermolecular interactions and binding affinity of furin with its inhibitors decanoyl-RVKR-chloromethylketone (CMK) and Naphthofluorescein which are reported experimentally [3]. The molecular docking studies show the binding affinity of two inhibitors with furin; docking scores for CMK and Naphthofluorescein are -9.87 and $-7.34 \mathrm{kcal} / \mathrm{mol}$ respectively. The docked complexes of both inhibitors form key interactions with furin and exhibits high docking scores. Further, the molecular dynamics (MD) simulation for both complexes have been performed to understand their stability, shows both inhibitors are stable in the active site region of furin. The RMSD and RMSF plots retrieved from the MD results confirm that CMK molecule having high stability on compare with the Naphthofluorescein. The investigation on furin inhibitors help to evaluate these drugs to be used as a repurposed drug for the SARS-CoV-2. The detailed study will be presented.

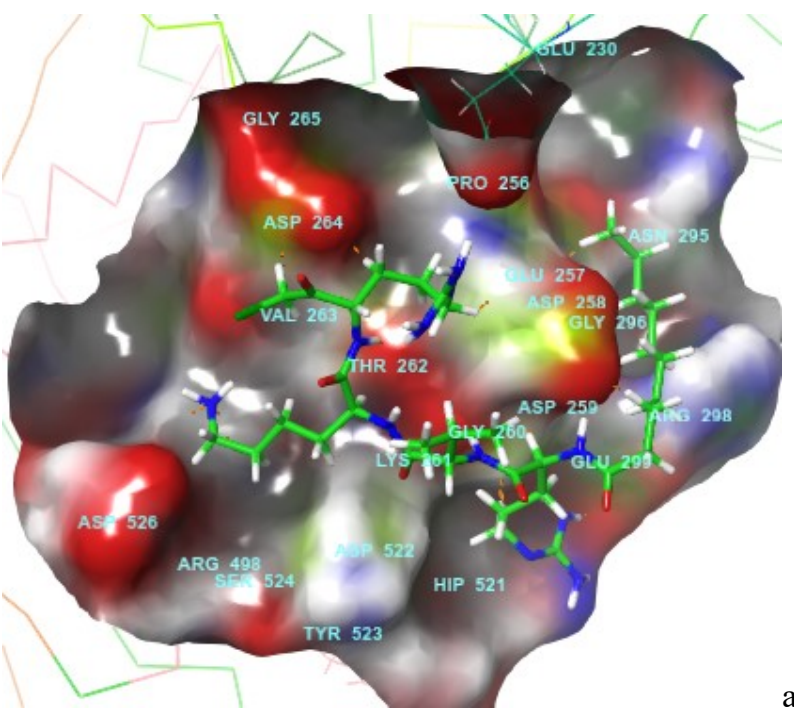

a)

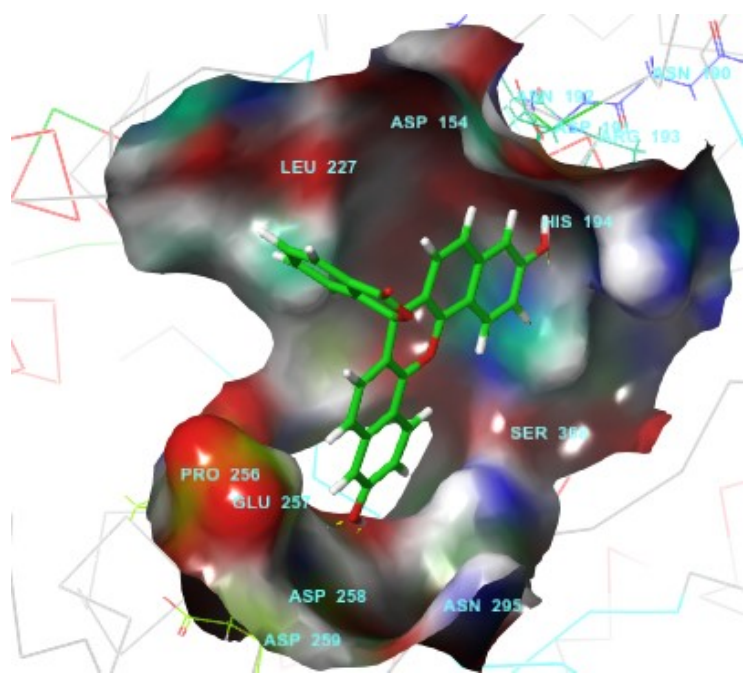

b)

Figure 1. Intermolecular interactions of (a) decanoyl-RVKR-chloromethylketone and (b) Naphthofluorescein with active site residues of Furin.

[1] Papa G, Mallery DL, Albecka A, et al (2021) Furin cleavage of SARS-CoV-2 Spike promotes but is not essential for infection and cell-cell fusion. PLoS Pathog 17:1-20.

[2] Wu C, Zheng M, Yang Y, et al (2020) Furin: A Potential Therapeutic Target for COVID-19. iScience 23:101642.

[3] Cheng YW, Chao TL, Li CL, et al (2020) Furin Inhibitors Block SARS-CoV-2 Spike Protein Cleavage to Suppress Virus Production and Cytopathic Effects. Cell Rep 33:108254.

Keywords: SARS-CoV-2; Spike protein; Furin; Repurposed drug; Molecular docking; Molecular dynamics 